\title{
PRACTICAL ANALYSIS PROCEDURE FOR COMPRESSIVE LOCAL BUCKLING OF SKIN SHEETS IN COMPOSITE PANELS
}

\author{
X. Ma ${ }^{1}$, J.W. Butterworth ${ }^{2, *}$ and G.C. Clifton ${ }^{3}$ \\ ${ }^{1}$ Postdoctoral Research Fellow, Department of Civil and Environmental Engineering, \\ University of Auckland, Auckland, New Zealand \\ ${ }^{2}$ Associate Professor, Department of Civil and Environmental Engineering, \\ University of Auckland, Auckland, New Zealand \\ *(Corresponding author: Email:jw.butterworth@auckland.ac.nz) \\ ${ }^{3}$ Associate Professor, Department of Civil and Environmental Engineering, \\ University of Auckland, Auckland, New Zealand
}

Received: 30 April 2007; Revised: 27 September 2007; Accepted: 3 October 2007

\begin{abstract}
This paper addresses the problem of determining the relationship between the properties of a composite wall panel, consisting of a thin sheet steel outer skin filled with light weight concrete or similar material, and the initiation of skin buckling. The skin sheet, considered as an infinite thin plate with two clamped lateral edges resting on a tensionless Winkler foundation, is simplified to a one-dimensional mechanical model by assuming a buckling mode function in terms of the lateral coordinates. After the governing differential equations for the plate sections in the contact and non-contact regions have been solved, the problem reduces to two nonlinear algebraic equations. Practical formulas for the buckling coefficient are developed in terms of a non-dimensional filler stiffness factor, defined in terms of the filler properties and its thickness to width ratio. Comparison of the results with existing theory and finite element analyses show good agreement.
\end{abstract}

Keywords: Compressive buckling; tensionless Winkler foundations; clamped rectangular plates; local buckling; composite panels

\section{INTRODUCTION}

Composite panels are widely used in the civil engineering field. Panels which consist of an external skin sheet containing a light-weight filler are likely under compressive stress conditions resulting from mechanical or thermal loading, to exhibit skin buckling in which sections of the skin become separated (delaminated) from the core material and buckle away from it. This paper addresses the problem of determining the relationship between the properties of a wall panel and the initiation of skin buckling. Although the initiation of skin buckling may not always lead to failure, or even measurable loss of strength or stiffness, it is a significant turning point in behaviour and appearance that needs to be identified and suppressed under in-service loading.

This type of buckling problem may be modelled as a skin sheet supported by a tensionless elastic filler material, leading to a problem which is difficult to analyse due to the nonlinearities resulting from the unilateral constraint and the complexity of contact effects.

Co [1] was one of the earliest researchers on the contact buckling problem, which was extended to a plate on tensionless rigid foundation recently by Shahwan \& Waas [2] and Smith et al. [3]. As practical applications, Wright [4] assumed a buckling mode function, Uy and Bradford [5] employed a finite strip model, Smith et al. $[6,7]$ combined theoretical methods and experimental research together in the local buckling analysis of composite steel-concrete members. Smith et al. [8] also studied the unilateral buckling problem under shear load. Chai [9] conducted analytical and experimental studies of post-local buckling response of unilaterally constrained thin plates. Ma et al. [10] studied the elasto-plastic post-buckling behaviour and the secondary buckling phenomenon of unilaterally constrained plates. Most of the existing literature has confined itself to the case of a plate on rigid constraints. 
However, in practical applications, the assumption of rigid constraints may sometimes be questionable. For example, to minimise self-weight, light filler materials are largely used in composite members, reducing the level of support available to the skin sheets. The reduction in buckling stresses may be overlooked if the filler is still regarded as a rigid constraint. We seek to establish the required stiffness of the filler in order to ensure sufficient support to enable the skin to efficiently carry compressive stress. Therefore, it is necessary to consider the elastic deformation of the filler when simulating the mechanical behaviour of light-weight composite members. Chai et al. [11] studied one-dimensional delamination buckling problems through a beam-column model, considering the support deformation at the beam ends. Based on potential energy theory, Shahwan \& Waas [12] presented an infinite plate model with only two unknowns, which was capable of considering elastic deformation of the foundation. In the literature, the governing equations for plates with simply supported edges and clamped-free edges are given. As part of a new approach, Holanda \& Goncalves [13] and Shen \& Li [14] simulated a numerical elastic contact post-buckling model for simply supported plates on tensionless foundations through perturbation and iteration techniques. Ma et al. [15] established an analytical model for compressive buckling of plates in unilateral contact. In general, numerical difficulties arise in the solution of nonlinear equations when the contact area is being determined, especially for a system with a large number of degrees of freedom (DOF).

In this paper, for practical use and to consider the effect of deformation of filler in the contact area, the skin sheets in composite panels are considered as infinitely long thin plates with immovable ends and two clamped lateral edges resting on tensionless Winkler foundations. With an assumed buckling mode function related to lateral coordinates, a one-dimensional mathematical model is deduced on the basis of Von Karman's equations. After solving the governing buckling equations of the plate sections in both the contact and non-contact regions, the problem reduces to two nonlinear algebraic equations. The buckling coefficient is then obtained in terms of a non-dimensional foundation stiffness factor.

\section{BUCKLING MODE OF THE SKIN SHEET}

(a)

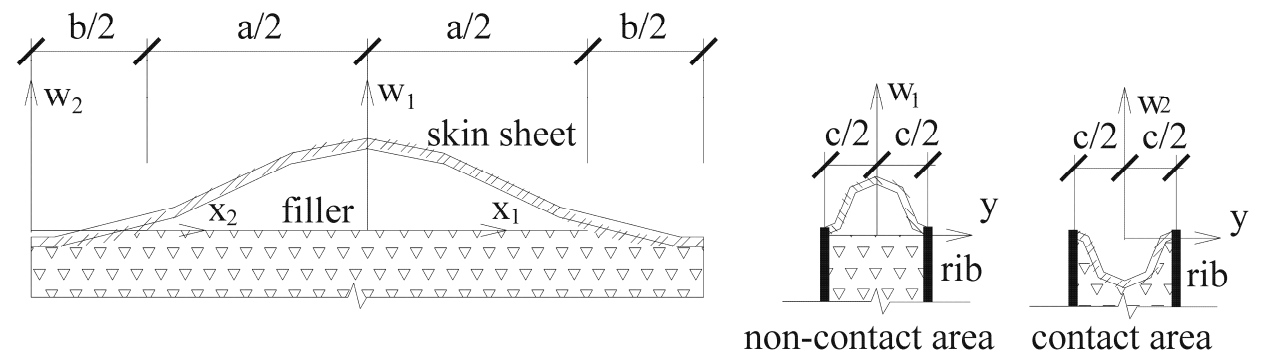

(b)
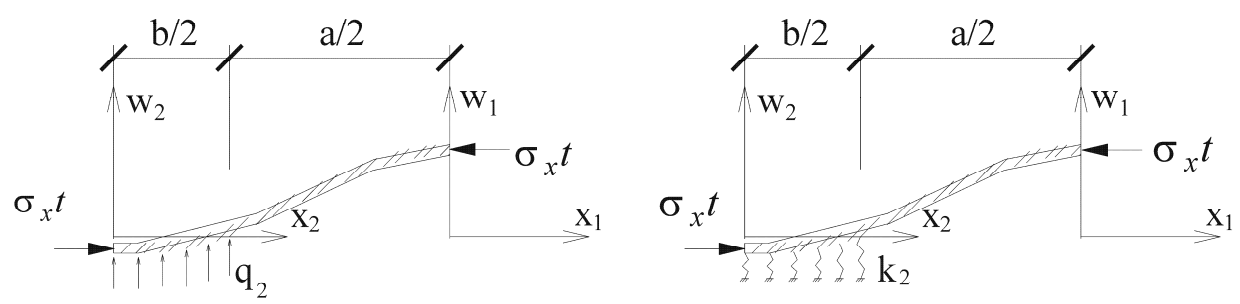

(a) Buckling Skin Sheet of One Wave Length

(b) Mechanical Model of Buckling Skin Sheet

Figure 1. Mechanical Model of Local Buckling Skin Sheet 
Considering the ribs as rigid constraints and ignoring the local effect due to boundary conditions of the two loaded edges, the buckling problem of a long skin sheet is reduced to a laterally clamped infinite plate model with periodically repeating buckles. Considering a single wave length plate section, we get the mechanical model of the skin sheet as shown in Figure 1a, where the length $(a+b)$ is one local buckle wave-length in the $x$ direction; a and $b$ are the non-contact length and the contact length between the skin sheet and the filler; and $c$ is the single local buckle wave-length in the $y$ direction. For practical analysis, the elastic filler may be simplified as a Winkler foundations (Figure 1b) with the foundation stiffness coefficient $k_{2}$ to be determined from the geometric and material properties of the filler.

For steel plates, the governing equation is

$$
\begin{aligned}
& w_{i, x_{i} x_{i} x_{i} x_{i}}+2 w_{i, x_{i} x_{i} y y}+w_{i, y y y y}+\frac{\sigma_{x} t}{D^{s}} w_{i, x_{i} x_{i}}=\frac{q_{i}}{D^{s}} \quad\left|x_{1}\right| \leq a / 2,\left|x_{2}\right| \leq b / 2 \quad i=1,2 \\
& D^{s}=\frac{E^{s} t^{3}}{12\left(1-v^{s^{2}}\right)} \\
& q_{i}=\left\{\begin{array}{c}
0 \quad\left|x_{1}\right| \leq a / 2 \quad i=1 \\
q_{2}\left(x_{2}, y\right) \quad\left|x_{2}\right| \leq b / 2 \quad i=2
\end{array}\right.
\end{aligned}
$$

where $D^{s}, E^{s}, v^{s}, t$ are the bending stiffness, elastic modulus, Poisson's ratio and thickness of the skin sheet. $\sigma_{x}$ is the normal direct stress in $x_{\mathrm{i}}$ direction; $q_{i}$ is the foundation reaction on the plate; the subscript ${ }_{i}$ indicates that the parameter relates to the plate section $i$ ( $i=1$ for non-contact plate section, $i=2$ for contact plate section); the subscripts, $x_{i}(, y)$ indicate partial differentiation $\partial / \partial x_{i}(\partial / \partial y)$, etc. The superscript 's' means the parameter is of the skin sheet. $w_{1}, x_{1}$ and $w_{2}, x_{2}$ are the vertical displacement and the local longitudinal coordinate in the non-contact and contact areas, respectively.

Assume $w_{i}\left(x_{i}, y\right)=f_{i}\left(x_{i}\right) g(y)$, and consider the filler material as a Winkler foundation, which means

$$
q_{i}\left(x_{i}, y\right)=-k_{i} f_{i}\left(x_{i}\right) g(y)
$$

Eq. 1 may be rewritten as

$$
f_{i}^{\prime \prime \prime \prime} g+2 f_{i}^{\prime \prime} g "+f_{i} g^{\prime \prime \prime \prime}+\frac{\sigma_{x} t}{D^{s}} f_{i}^{\prime \prime} g=-\frac{k_{i}}{D^{s}} f_{i} g \quad i=1,2
$$

where $f_{i}, g$ are the longitudinal buckling mode function and the lateral buckling mode function; $k_{1}(=0)$ and $k_{2}$ denote the stiffness factors of the Winkler foundation. The superscript ' denotes differentiation with respect to $x$ or $y$.

The boundary condition of the problem is

$$
g( \pm c / 2)=g^{\prime}( \pm c / 2)=0
$$


The continuity condition between $f_{1}, f_{2}$ is

$$
\begin{aligned}
& f_{1}(-a / 2)=f_{2}(b / 2) \\
& f_{1}^{\prime}(-a / 2)=f_{2}^{\prime}(b / 2) \\
& f_{1}^{\prime \prime}(-a / 2)=f_{2}^{\prime \prime}(b / 2) \\
& f_{1}^{\prime \prime \prime}(-a / 2)=f_{2}^{\prime \prime \prime}(b / 2)
\end{aligned}
$$

To satisfy the boundary condition of Eq. 6, the lateral (buckling) mode function $g(y)$ of a clamped plate may be assumed as (Ma et al. [15])

$$
g(y)=\left[1 / 4-(y / c)^{2}\right]^{2}
$$

Taking the integral of Eq. 5 after multiplying both sides by function $g(y)$, and assuming

$$
\begin{aligned}
& f_{i}\left(x_{i}\right)=\widetilde{f}_{i}\left(\xi_{i}\right), \xi_{1}=x_{1} / a, \phi_{1}=a / c, \xi_{2}=x_{2} / b, \phi_{2}=b / c, \widetilde{K}=\frac{c^{2} \sigma_{x} t}{\pi^{2} D^{s}} \text { we get } \\
& \widetilde{f}_{i}^{\prime \prime \prime}\left(\xi_{i}\right)-\phi_{i}^{2}\left(24-\pi^{2} \widetilde{K}^{\prime} \widetilde{f}_{i}^{\prime \prime}\left(\xi_{i}\right)+504 \phi_{i}^{4}\left(1+\widetilde{k}_{i}\right) \widetilde{f}_{i}\left(\xi_{i}\right)=0 \quad\left|\xi_{i}\right| \leq 1 / 2 \quad i=1,2\right.
\end{aligned}
$$

where $\xi_{i}$ is the non-dimensional longitudinal coordinate variable; $\widetilde{f}_{i}$ is the longitudinal buckling mode function in terms of the non-dimensional variable $\xi_{i} ; \phi_{i}$ is the aspect ratio of the plate section; $\widetilde{K}$ is the load coefficient; $\tilde{k}_{1}=0 ; \quad \tilde{k}_{2}=k_{r}=\frac{c^{4} k_{2}}{504 D^{s}}$ is the relative Winkler spring coefficient, which may be obtained based on the geometric and material properties of the filler.

The symmetric solution of Eq. 9 may be written as

$$
\widetilde{f}_{i}\left(\xi_{i}\right)=A_{1 i} f_{1 i}+A_{2 i} f_{2 i}
$$

where $A_{1 i}, A_{2 i}$ are coefficients to be determined; the functions $f_{1 i}, f_{2 i}$ may be obtained based on the following three cases

Case $1 \quad \Delta_{i}=\left(\frac{\pi^{2} \widetilde{K}}{8}-3\right)^{2}-31.5\left(1+\widetilde{k}_{i}\right)>0$

$f_{1 i}\left(\xi_{i}\right)=\cos \left(\alpha_{i} \xi_{i}\right)$

$f_{2 i}\left(\xi_{i}\right)=\cos \left(\beta_{i} \xi_{i}\right)$

$\alpha_{i}, \beta_{i}=2 \phi_{i}\left[\frac{\pi^{2} \widetilde{K}}{8}-3 \pm \sqrt{\Delta_{i}}\right]^{1 / 2}$

$\underline{\text { Case } 2} \Delta_{i}=\left(\frac{\pi^{2} \tilde{K}}{8}-3\right)^{2}-31.5\left(1+\tilde{k}_{i}\right)=0$ 


$$
\begin{aligned}
& f_{1 i}\left(\xi_{i}\right)=\cos \left(\alpha_{i} \xi_{i}\right) \\
& f_{2 i}\left(\xi_{i}\right)=\xi_{i} \sin \left(\alpha_{i} \xi_{i}\right) \\
& \alpha_{i}=2 \phi_{i}\left[\frac{\pi^{2} \widetilde{K}}{8}-3\right]^{1 / 2}
\end{aligned}
$$

Case $3 \quad \Delta_{i}=\left(\frac{\pi^{2} \widetilde{K}}{8}-3\right)^{2}-31.5\left(1+\widetilde{k}_{i}\right)<0$

$f_{1 i}\left(\xi_{i}\right)=\left(e^{\alpha_{i} \xi_{i}}+e^{-\alpha_{i} \xi_{i}}\right) \cos \left(\beta_{i} \xi_{i}\right)$

$f_{2 i}\left(\xi_{i}\right)=\left(e^{\alpha_{i} \xi_{i}}-e^{-\alpha_{i} \xi_{i}}\right) \sin \left(\beta_{i} \xi_{i}\right)$

$\alpha_{i}, \beta_{i}=2 \phi_{i}\left[\sqrt{\left(\frac{\pi^{2} \widetilde{K}}{8}-3\right)^{2}-\Delta_{i}} \mp\left(\frac{\pi^{2} \widetilde{K}}{8}-3\right)\right]^{1 / 2}$

The continuity condition of Eq. 7 may be rewritten as

$\widetilde{f}_{1}(-1 / 2)=\widetilde{f}_{2}(1 / 2)$

$\widetilde{f}_{1}^{\prime}(-1 / 2) / a=\widetilde{f}_{2}^{\prime}(1 / 2) / b$

$\widetilde{f}_{1}^{\prime \prime}(-1 / 2) / a^{2}=\widetilde{f}_{2}^{\prime \prime}(1 / 2) / b^{2}$

$\widetilde{f}_{1}^{\prime \prime \prime}(-1 / 2) / a^{3}=\widetilde{f}_{2}^{\prime \prime \prime}(1 / 2) / b^{3}$

Eq. 14 may be expressed in matrix form as

$$
\left[\begin{array}{cccc}
f_{11}(-1 / 2) & f_{21}(-1 / 2) & -f_{12}(1 / 2) & -f_{22}(1 / 2) \\
f_{11}^{\prime}(-1 / 2) / a & f_{21}^{\prime}(-1 / 2) / a & -f_{12}^{\prime}(1 / 2) / b & -f_{22}^{\prime}(1 / 2) / b \\
f_{11}^{\prime \prime}(-1 / 2) / a^{2} & f_{21}^{\prime \prime}(-1 / 2) / a^{2} & -f_{12}^{\prime \prime}(1 / 2) / b^{2} & -f_{22}^{\prime \prime}(1 / 2) / b^{2} \\
f_{11}^{\prime \prime \prime}(-1 / 2) / a^{3} & f_{21}^{\prime \prime}(-1 / 2) / a^{3} & -f_{12}^{\prime \prime \prime}(1 / 2) / b^{3} & -f_{22}^{\prime \prime \prime}(1 / 2) / b^{3}
\end{array}\right]\left[\begin{array}{l}
A_{11} \\
A_{21} \\
A_{12} \\
A_{22}
\end{array}\right]=\left[\begin{array}{l}
0 \\
0 \\
0 \\
0
\end{array}\right]
$$

For a non-trivial solution of Eq. 15, we require that the determinant of the coefficient matrix should vanish,

$$
\left|\begin{array}{cccc}
f_{11}(-1 / 2) & f_{21}(-1 / 2) & -f_{12}(1 / 2) & -f_{22}(1 / 2) \\
f_{11}^{\prime}(-1 / 2) / a & f_{21}^{\prime}(-1 / 2) / a & -f_{12}^{\prime}(1 / 2) / b & -f_{22}^{\prime}(1 / 2) / b \\
f_{11}^{\prime \prime}(-1 / 2) / a^{2} & f_{21}^{\prime \prime}(-1 / 2) / a^{2} & -f_{12}^{\prime \prime}(1 / 2) / b^{2} & -f_{22}^{\prime \prime}(1 / 2) / b^{2} \\
f_{11}^{\prime \prime \prime}(-1 / 2) / a^{3} & f_{21}^{\prime \prime \prime}(-1 / 2) / a^{3} & -f_{12}^{\prime \prime \prime}(1 / 2) / b^{3} & -f_{22}^{\prime \prime \prime}(1 / 2) / b^{3}
\end{array}\right|=0
$$

Considering that the displacement on the borderline separating contact and non-contact areas must be zero, leads to an additional equation which must be satisfied 


$$
\tilde{f}_{1}(-1 / 2)=A_{11} f_{11}(-1 / 2)+A_{21} f_{21}(-1 / 2)=0
$$

Solving Eq. 16, we obtain values of $\widetilde{K}, \phi_{2}$ for different $\phi_{1}$. The true value of $\phi_{1}$ is that which minimizes $\widetilde{K}$. The minimum $\widetilde{K}$ is the buckling coefficient $K_{c r}$, which may be simulated by the numerically fitted formula

$$
K_{c r}=\left\{\begin{array}{cc}
6.97 & k_{r}<0.001 \\
0.0825\left(\log k_{r}\right)^{3}+0.614\left(\log k_{r}\right)^{2}+1.509\left(\log k_{r}\right)+8.202 & 0.001 \leq k_{r}<1 \\
0.0671\left(\log k_{r}\right)^{3}-0.608\left(\log k_{r}\right)^{2}+1.813\left(\log k_{r}\right)+8.202 & 1 \leq k_{r}<1000 \\
9.98 & 1000 \leq k_{r}
\end{array}\right.
$$

and the corresponding compressive stress is the critical stress

$$
\sigma_{c r}=\frac{\pi^{2} K_{c r} D^{s}}{c^{2} t}=\frac{\pi^{2} K_{c r} E^{s}}{12\left(1-v^{s^{2}}\right)}\left(\frac{t}{c}\right)^{2}
$$

The analytical results (Eq. 16), fitted results (Eq. 17a) of $K_{c r}$ related to $k_{r}$ and the corresponding $\phi_{1}, \phi_{2}$ are shown in Figure 2. To verify the method in the paper, the $K_{c r}$ results are compared with ABAQUS results in Figure 2a, where the ABAQUS models are assumed to be partly constrained plates (Figure 1b) with the same constrained and non-constrained lengths as the analytical results of $\phi_{1}, \phi_{2}$ in Figure $2 b$.

To verify the solutions above, consider two extreme conditions: when $k_{r}$ is very small, the skin sheet is similar to a non-contact long plate with two immovable ends and the other two edges built-in (plate 1); when $k_{r}$ is very large, the skin sheet is similar to a plate buckling in one half-wave-length, with four edges built-in (plate 2). The comparison between the results of the method in this paper and existing theory (Bloom \& Coffin [16]; Uy \& Bradford [5]) are shown in Table 1:

(a)

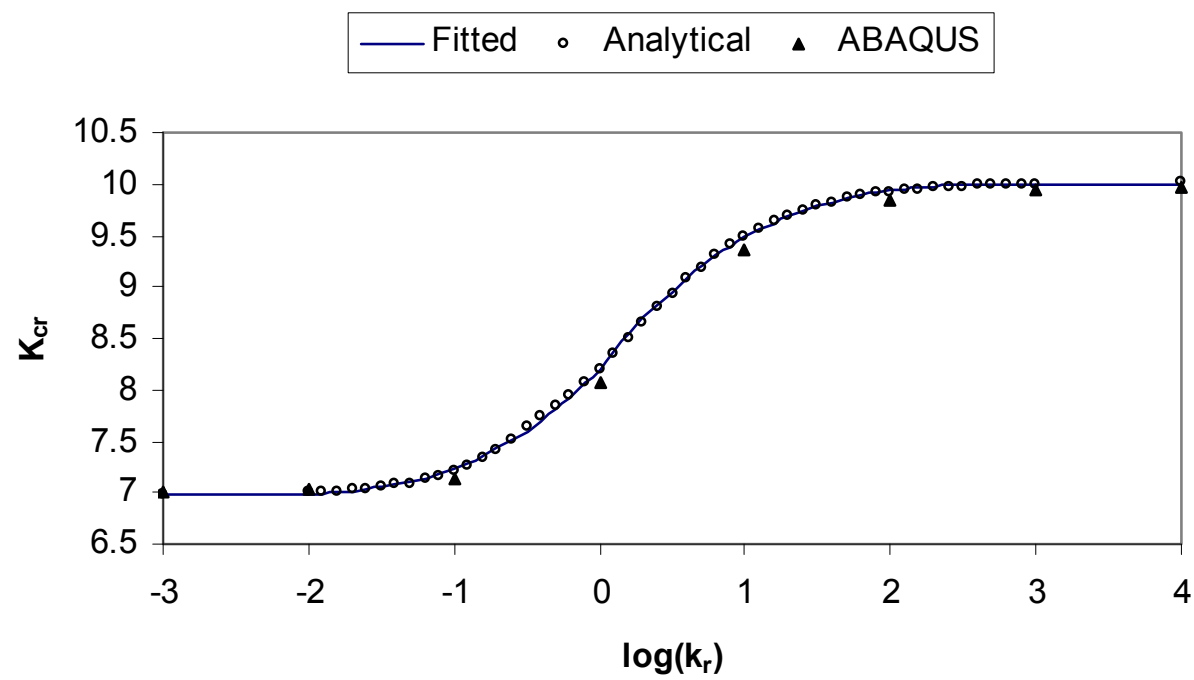


(b)

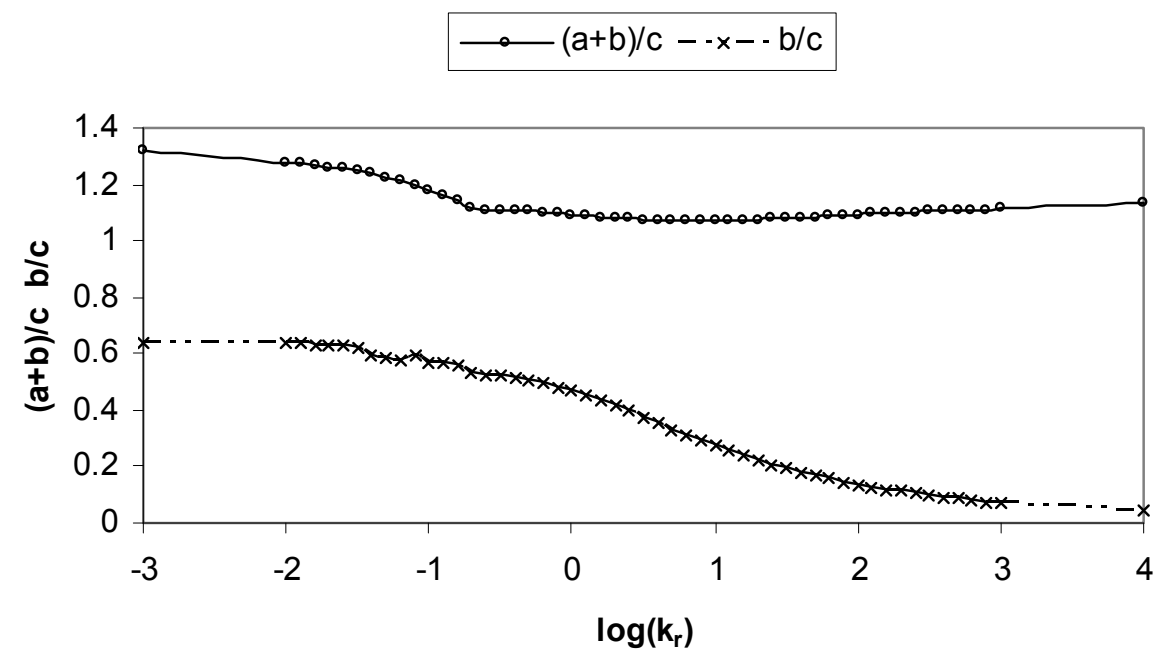

(a) Relationship between $K_{c r}$ and $\log k_{r}$ (b) Relationship between $\phi_{1}, \phi_{2}$ and $\log k_{r}$

Figure 2. Numerical Results for Analytical Models

Table 1. Comparative Results

\begin{tabular}{|c|c|c|c|c|c|c|c|}
\hline \multicolumn{4}{|c|}{ Method in the paper } & \multicolumn{4}{|c|}{ Existing theory } \\
\hline$k_{r}$ & $K_{c r}$ & $(a+b) / c$ & $b / c$ & & $K_{c r}$ & $(a+b) / c$ & $b / c$ \\
\hline $10^{-3}$ & $\begin{array}{l}6.98 \text { (Eq. 16) } \\
6.97 \text { (Eq.17a) }\end{array}$ & 1.32 & 0.64 & plate 1 & 6.97(Bloom) & 1.32 & 0.66 \\
\hline $10^{6}$ & $\begin{array}{l}10.01(\text { Eq.16) } \\
9.98(\text { Eq. } 17 \mathrm{a})\end{array}$ & 1.14 & 0.01 & plate 2 & $\begin{array}{l}9.80 \text { (Bloom) } \\
10.3(\mathrm{Uy})\end{array}$ & $\begin{array}{l}1.20 \text { (Bloom) } \\
1.0(\mathrm{Uy})\end{array}$ & 0 \\
\hline
\end{tabular}

For finite plates resting on tensionless foundations, ABAQUS allows unilateral contact buckling analysis. The buckling coefficients of clamped plates with different aspect ratios $(2,4)$ are compared with the results of an infinite plate model in Figure 3, showing that the infinite plate model is applicable to plates with aspect ratios greater than about 4 .
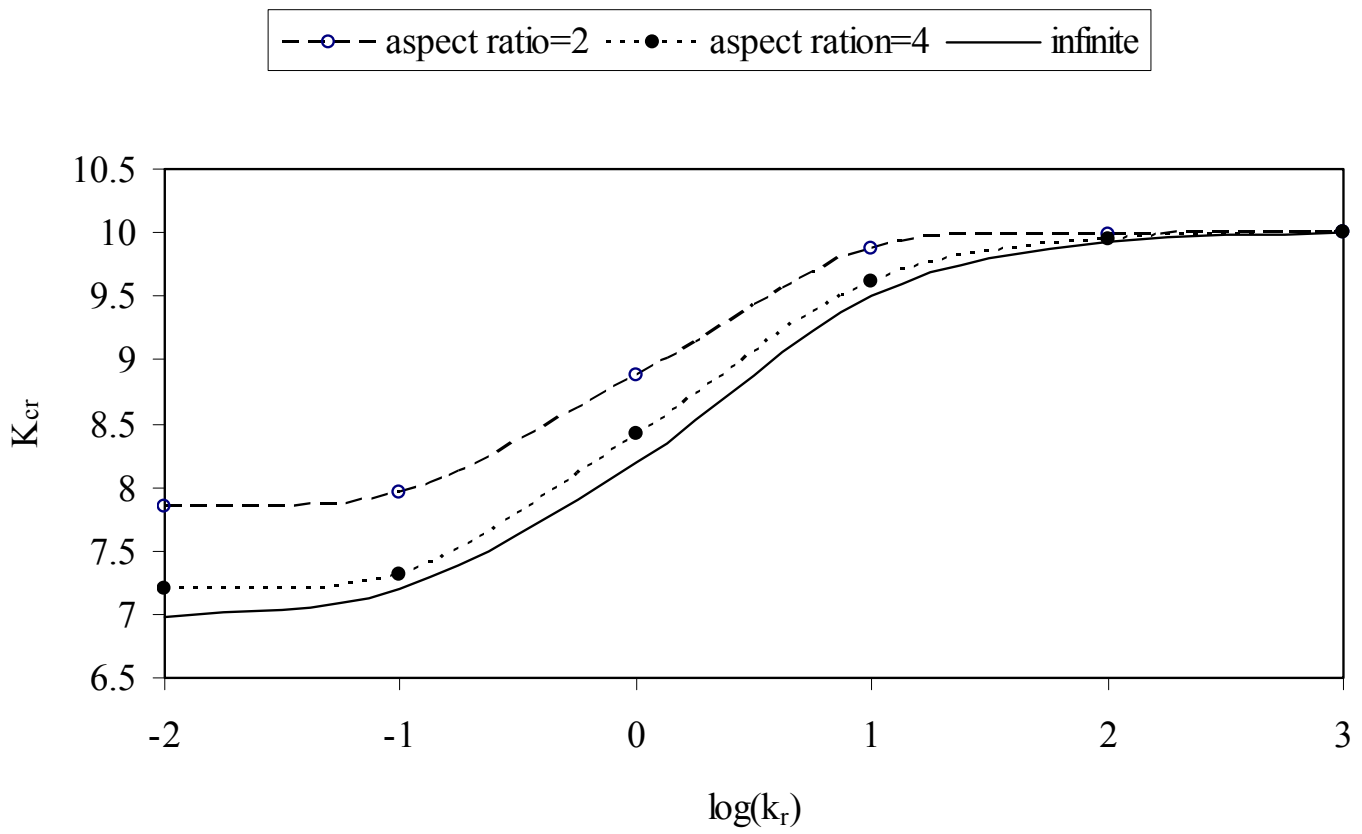

Figure 3. Buckling Coefficients of Plates with Varying Foundation Stiffness Coefficients and Different Aspect Ratios 


\section{MECHANICAL MODEL FOR FILLER MATERIAL}

In the simplified buckling model of the skin sheet, the 3-d continuum filler was represented by tensionless Winkler springs. The objective of this section is to deduce an appropriate stiffness coefficient for the Winkler spring based on the geometric and elastic properties of the filler.

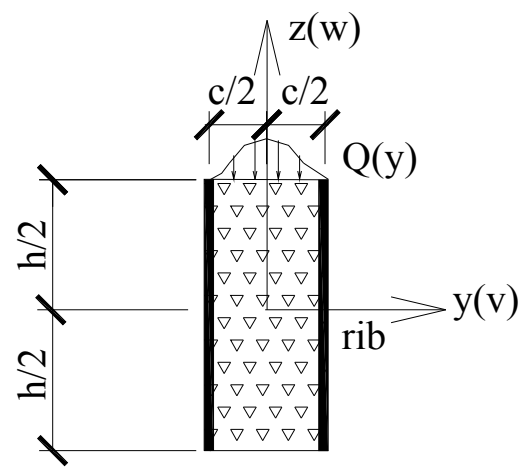

Figure 4. Mechanical Model of the Filler

Assuming the cross section of the filler at the position $x_{2}$ is in a state of plane strain (Figure 4), the boundary condition of the filler may be expressed as

$$
\begin{aligned}
& w^{f}=w_{, y}^{f}=0 \quad y= \pm c / 2 \\
& v^{f}=0 \quad y= \pm c / 2 \\
& \int_{-\frac{c}{2}}^{\frac{c}{2}} v^{f} d y=0
\end{aligned}
$$

where $v^{f}, w^{f}$ are the displacement functions of the filler material in the $\mathrm{y}, \mathrm{z}$ directions respectively. The superscript "f, means the parameter is of the filler.

Considering the boundary conditions above, the displacement functions of the filler may be assumed as

$$
\begin{aligned}
& v^{f}=\sum_{m=1}^{M_{v}^{f}} \sum_{k=0}^{K_{v}^{f}} A_{m k}^{f} g_{v m}^{f}(y)(z / h)^{k} \\
& w^{f}=g^{f}(y) \sum_{k=0}^{K_{w}^{f}} B_{k}^{f}(z / h)^{k} \\
& g_{v m}^{f}(y)=\sin (2 m \pi y / c)
\end{aligned}
$$

where $A_{m k}^{f}, B_{k}^{f}$ are displacement coefficients to be determined.

Considering the contact condition between the skin sheet and the surface of the filler, both vertical displacements must have the same function, which means 


$$
g^{f}(y)=g(y)=\left[1 / 4-(y / c)^{2}\right]^{2}
$$

The potential energy of the filler material may be expressed as,

$$
\begin{aligned}
& \Pi^{f}=\iint_{A} \Lambda^{f}\left(v^{f}, w^{f}\right) d A-\int_{z=h / 2} Q(y) w_{0}^{f}(y) d y \\
& \Lambda^{f}=\frac{E^{f}}{2\left(1+v^{f}\right)}\left[v_{, y}^{f^{2}}+w_{, z}^{f^{2}}+\frac{1}{1-2 v^{f}}\left(v_{, y}^{f}+w_{, z}^{f}\right)^{2}+\frac{1}{2}\left(v_{, z}^{f}+w_{, y}^{f}\right)^{2}\right] \\
& w_{0}^{f}=g^{f}(y) \sum_{k=0}^{K_{w}^{f}} B_{k}^{f}(1 / 2)^{k} \\
& Q(y)=-q_{2}\left(x_{2}, y\right)=k_{2} f_{2}\left(x_{2}\right) g(y)
\end{aligned}
$$

where $\Lambda^{f}$ is the potential energy density function; $E^{f}, v^{f}$ denote the elastic modulus and Poisson's ratio of the filler material, $w_{0}^{f}$ is the vertical displacement at the surface of the filler, $Q(y)$ is the reaction of $q_{2}\left(x_{2}, y\right)$.

The solution of the problem must minimise the potential energy, which means

$$
\begin{aligned}
& \Pi_{, A_{m k}^{f}}^{f}=0 \quad m=1, \cdots M_{v}^{f} ; k=0,1, \cdots, K_{v}^{f} \\
& \Pi_{, B_{k}^{f}}^{f}=0 \quad k=0,1, \cdots, K_{w}^{f}
\end{aligned}
$$

Eqs. 29, 30 may be expressed in the following matrix form

$$
\left[\begin{array}{ll}
K^{A^{f} A^{f}} & K^{A^{f} B^{f}} \\
K^{B^{f} A^{f}} & K^{B^{f} B^{f}}
\end{array}\right]\left[\begin{array}{l}
A^{f} \\
B^{f}
\end{array}\right]-\left[\begin{array}{c}
0 \\
F_{c}^{f}
\end{array}\right]=0
$$

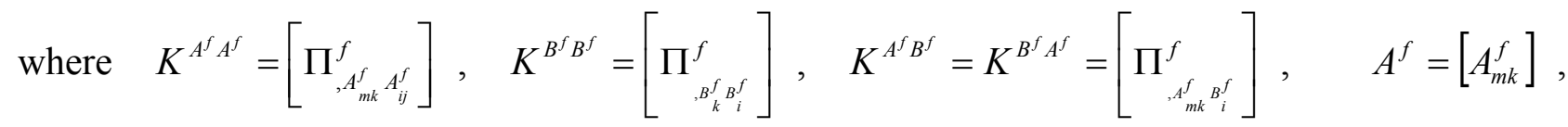
$B^{f}=\left[B_{k}^{f}\right], \quad F_{c}^{f}=\left[(1 / 2)^{k} \int_{|y| \leq c / 2} Q(y) g^{f}(y) d y\right]$

Expanding Eq. 31, we obtain

$$
\begin{aligned}
& B^{f}=\left[\hat{K}^{B^{f} B^{f}}\right]^{-1} F_{c}^{f} \\
& \hat{K}^{B^{f} B^{f}}=K^{B^{f} B^{f}}-K^{B^{f} A^{f}}\left[K^{A^{f} A^{f}}\right]^{-1} K^{A^{f} B^{f}}
\end{aligned}
$$

Thus Eq. 27 may be rewritten as 
$w_{0}^{f}\left(x_{2}, y\right)=\frac{c k_{2}}{E^{f}} d_{0}^{f} f_{2}\left(x_{2}\right) g^{f}(y)$

where non-dimensional factor $d_{0}^{f}$ may be expressed as

$d_{0}^{f}=\frac{E^{f}\left[(1 / 2)^{k}\right]^{T}\left[\hat{K}^{B^{f} B^{f}}\right]^{-1}\left[(1 / 2)^{k}\right]}{630}$

Considering that both the plate and the filler surface in the contact area have the same vertical displacement,

$w_{0}^{f}\left(x_{2}, y\right)=w_{2}\left(x_{2}, y\right)=f_{2}\left(x_{2}\right) g(y)$

Comparing Eqs. 24, 34, 36 and 9, we get

$k_{2}=\frac{E^{f}}{c \cdot d_{0}^{f}}$

$\widetilde{k}_{2}=k_{r}=\frac{1-v^{s^{2}}}{42 d_{0}^{f}} \frac{E^{f}}{E^{s}}\left(\frac{c}{t}\right)^{3}$

Non-dimensional factor $d_{0}^{f}$ related to $\mathrm{h} / \mathrm{c}$ and $v^{f}$ is shown in Table 2.

To verify the potential energy method (PEM) above, the displacement of an example case is compared with ABAQUS results in Figure 5, where $c=1, E^{f}=1, v^{f}=0, Q(y)=g(y)$.

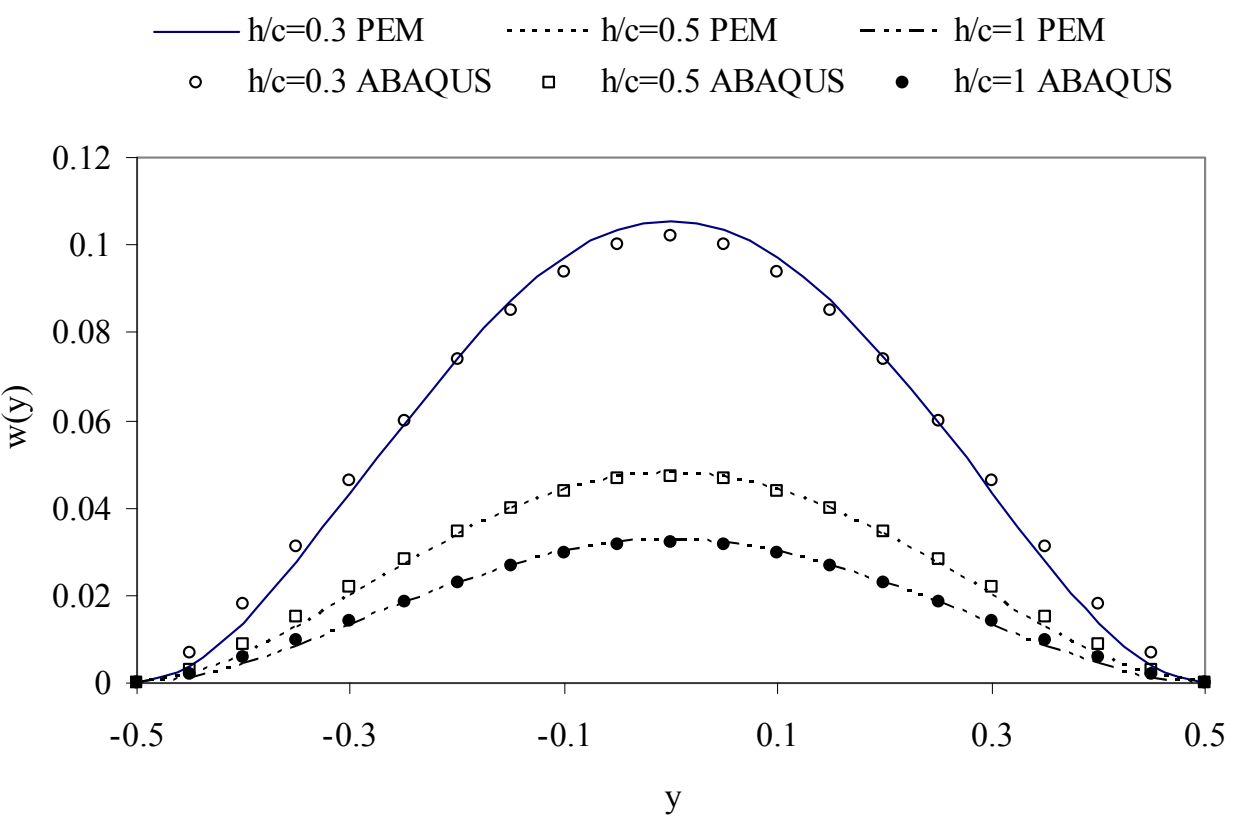

Figure 5. Comparison of Filler Displacement Profiles from PEM and ABAQUS Analyses 
Table 2. Non-dimensional Factor $d_{0}^{f}$

\begin{tabular}{|c|c|c|c|c|c|c|c|c|}
\hline $\mathbf{h} / \mathbf{c}$ & $\mathbf{0 . 3}$ & $\mathbf{0 . 4}$ & $\mathbf{0 . 5}$ & $\mathbf{0 . 6}$ & $\mathbf{0 . 7}$ & $\mathbf{0 . 8}$ & $\mathbf{0 . 9}$ & $\mathbf{1 . 0}$ \\
\hline$v^{f}=0.0$ & 1.69 & 1.03 & 0.77 & 0.65 & 0.59 & 0.55 & 0.53 & 0.52 \\
\hline$v^{f}=0.1$ & 1.73 & 1.06 & 0.80 & 0.67 & 0.61 & 0.57 & 0.55 & 0.54 \\
\hline$v^{f}=0.2$ & 1.72 & 1.07 & 0.81 & 0.68 & 0.61 & 0.57 & 0.55 & 0.53 \\
\hline$v^{f}=0.3$ & 1.62 & 1.03 & 0.79 & 0.65 & 0.59 & 0.54 & 0.52 & 0.50 \\
\hline$v^{f}=0.4$ & 1.40 & 0.93 & 0.71 & 0.59 & 0.52 & 0.47 & 0.44 & 0.42 \\
\hline
\end{tabular}

\section{PRACTICAL DESIGN PROCEDURE AND EXAMPLE}

For practical design, the effective width is often employed to determine the compressive loading capacity of postbuckling thin plates. According to the Australian/New Zealand Standard "Cold-formed steel structures" (AS/NZS 4600:1996 [17]), the effective width factor may be expressed as

$\rho=\left\{\begin{array}{cc}1 & \lambda \leq 0.673 \\ (1-0.22 / \lambda) / \lambda & \lambda>0.673\end{array}\right.$

where $\rho$ is the effective width factor; $\lambda=\sqrt{f_{y} / \sigma_{c r}} ; f_{\mathrm{y}}$ is the yield stress of skin material.

To illustrate the practical application of the simplified design procedure presented above, consider an example of a skin sheet with $t / c=1 / 200, E^{s}=2.05 \times 10^{5} \mathrm{MPa}, v^{s}=0.3, f_{\mathrm{y}}=300 \mathrm{MPa}$ and a filler with parameters of $\mathrm{h} / \mathrm{c}=0.5, v^{f}=0.2, E^{f} / E^{s}=0.0005$.

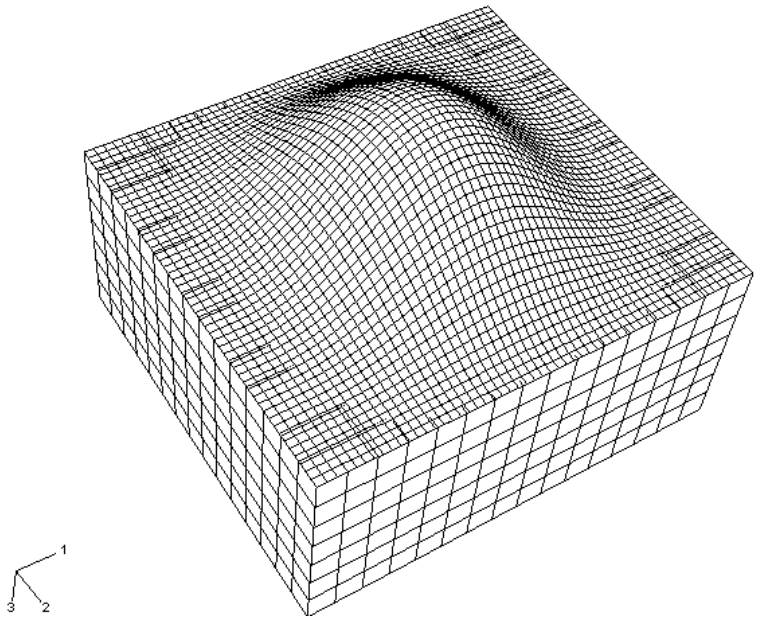

Figure 6. Buckling Mode of Skin Sheet Partly Constrained by Elastic Foundations (an ABAQUS Model)

According to Table 2 and Eq. 37, $d_{0}^{f}=0.81, k_{r}=106.9$. Based on Eq. 17a, the resulting buckling coefficient $K_{c r}=9.92$. Thus, based on Eqs. $17 \mathrm{~b}$ and 39 , the critical compressive stress $\sigma_{c r}=45.95 \mathrm{MPa}$ and the effective width factor $\rho=0.358$. The critical compressive stress agrees well with the ABAQUS result $\sigma_{c r}=45.11 \mathrm{MPa}$, where the ABAQUS model is assumed to be a partly constrained skin sheet with the same aspect ratio and contact length as the analytical model, i.e. $a+b=1.10 c$ and $b=0.136 c$ (according to Figure $2 \mathrm{~b}$ ). The buckling mode of the skin sheet resting on solid foundations is shown in Figure 6. 


\section{CONCLUSIONS}

A simplified contact model has been presented to consider local buckling behaviour of skin sheets unilaterally constrained by elastic filler in composite panels. After the governing differential equations for the plate sections in the contact and non-contact regions have been solved, the buckling coefficient is obtained in terms of a non-dimensional Winkler foundation stiffness factor, defined in terms of the filler properties and its thickness to width ratio. Good agreement with existing solutions and ABAQUS results has been demonstrated. Finally, numerically fitted formulas for buckling coefficient and design tables for Winkler foundation stiffness factor have been established for practical use.

\section{ACKNOWLEDGMENTS}

The authors are grateful for the financial support of the New Zealand Foundation for Research, Science and Technology.

\section{REFERENCES}

[1] Co, C., "Bifurcation Theory for Elastic Plates Subjected to Unilateral Conditions", Journal of Mathematical Analysis and Applications, 1977, Vol. 60, No. 2, pp. 435-448.

[2] Shahwan, K.W. and Waas, A.M., "A Mechanical Model for the Buckling of Unilaterally Constrained Rectangular Plates", International Journal of Solids and Structures, 1994, Vol. 31, No. 1, pp. 75-87.

[3] Smith, S.T., Bradford M.A. and Oehlers, D.J., "Numerical Convergence of Simple and Orthogonal Polynomials for the Unilateral Plate Buckling Problem Using the Rayleigh-Ritz Method", International Journal for Numerical Methods in Engineering, 1999, Vol. 44, No. 11, pp. 1685-1707.

[4] Wright, H.D., "Local Stability of Filled and Encased Steel Section", Journal of Structural Engineering, ASCE, 1995, Vol. 12, No. 1, pp. 1382-1388.

[5] Uy, B. and Bradford M.A., "Elastic Local Buckling of Steel Plates in Composite Steel-Concrete Members", Engineering Structures, 1996, Vol. 18, No. 3, pp.193-200.

[6] Smith, S.T., Bradford M.A. and Oehlers, D.J., "Local Buckling of Side-plated Reinforced-Concrete Beams I: Theoretical Study", Journal of Structural Engineering, ASCE, 1999, Vol. 125, No. 6, pp. 625-634.

[7] Smith, S.T., Bradford M.A. and Oehlers, D.J., "Local Buckling of Side-plated Reinforced-Concrete Beams II: Experimental Study", Journal of Structural Engineering, ASCE, 1999, Vol. 125, No. 6, pp. 635-643.

[8] Smith, S. T., Bradford M. A. and Oehlers, D.J., "Elastic Buckling of Unilaterally Constrained Rectangular Plates in Pure Shear", Engineering Structures, 1999, Vol. 21, No.5, pp. 443-453.

[9] Chai, H., "Contact Buckling and Postbuckling of Thin Rectangular Plates", Journal of Mechanics and Physics of Solids, 2001, Vol. 49, No. 2, pp.209-230.

[10] Ma, X., Butterworth, J.W. and Clifton, G.C., "Elasto-plastic Postbuckling Analysis of Plates Resting on Tensionless Foundations", Proceedings of 19th Australasian Conference on the Mechanics of Structures and Materials, Christchurch, New Zealand, 2006, pp. 103-108.

[11] Chai, H., Babcock, C.D. and Knauss, W.G., "One Dimensional Modeling of Failure in Laminated Plates by Delamination Buckling", International Journal of Solids and Structures, 1981, Vol. 17, No. 11, pp. 1069-1083.

[12] Shahwan, K.W. and Waas, A.M., "Buckling on Unilaterally Constrained Infinite Plates", Journal of Engineering Mechanics, ASCE, 1998, Vol. 124, No. 2, pp. 127-136. 
[13] Holanda, A.S. de, Goncalves, P.B., "Postbuckling Analysis of Plates Resting on a Tensionless Elastic Foundation", Journal of Engineering Mechanics, ASCE, 2003, Vol. 129, No. 4, pp. 438-448.

[14] Shen, H. and Li, Q.S., "Postbuckling of Shear Deformable Laminated Plates Resting on a Tensionless Elastic Foundation Subjected to Mechanical or Thermal Loading", International Journal of Solids and Structures, 2004, Vol. 41, No.16-17, pp. 4769-4785.

[15] Ma, X., Butterworth, J.W. and Clifton, G.C., "Compressive Buckling Analysis of Plates in Unilateral Contact”, International Journal of Solids and Structures, 2007, Vol. 44, No. 9, pp. 2852-2862.

[16] Bloom, F. and Coffin, D., "Handbook of Thin Plate Buckling and Postbuckling", Chapman \& Hall/CRC, 2001.

[17] AS/NZS 4600:1996. Australian/New Zealand Standard, "Cold-formed Steel Structures", Standards New Zealand and Standards Australia. 